\title{
Traumatic priapism: an unusual cycling injury
}

\author{
A Golash, R Gray, M S T Ruttley, B J Jenkins
}

\begin{abstract}
A case is reported of a 35 year old man who sustained an injury to the perineum in a cycling accident which resulted in a traumatic priapism. After confirmation of the diagnosis by Doppler sonography and angiography, therapeutic selective arterial embolisation was followed by successful detumescence of the penis and subsequent return of normal erectile function. It is suggested that percutaneous embolisation of the lacerated cavernosal artery is a safe and effective minimally invasive treatment for this uncommon condition.

(Br F Sports Med 2000;34:310-311)
\end{abstract}

Keywords: priapism; penis; embolisation; perineum; cavernosal artery; cycling

\section{Case report}

A fit 35 year old keen amateur cyclist sustained a blunt injury to the perineum on being thrown on to the handlebars of his mountain bicycle. He presented 10 days later with a painless but partial erection that had been present since the accident. He was unable to achieve a complete erection or detumescence, even though he had ejaculated painlessly twice since the injury.

Physical examination showed a partial priapism with no tenderness or bruising. The glans penis was soft and the cavernous bodies compressible. A colour Doppler scan showed abnormally high arterial and venous flow in the corpora, although a fistula was not observed. An internal pudendal arteriogram performed by the Seldinger technique under local anaes-
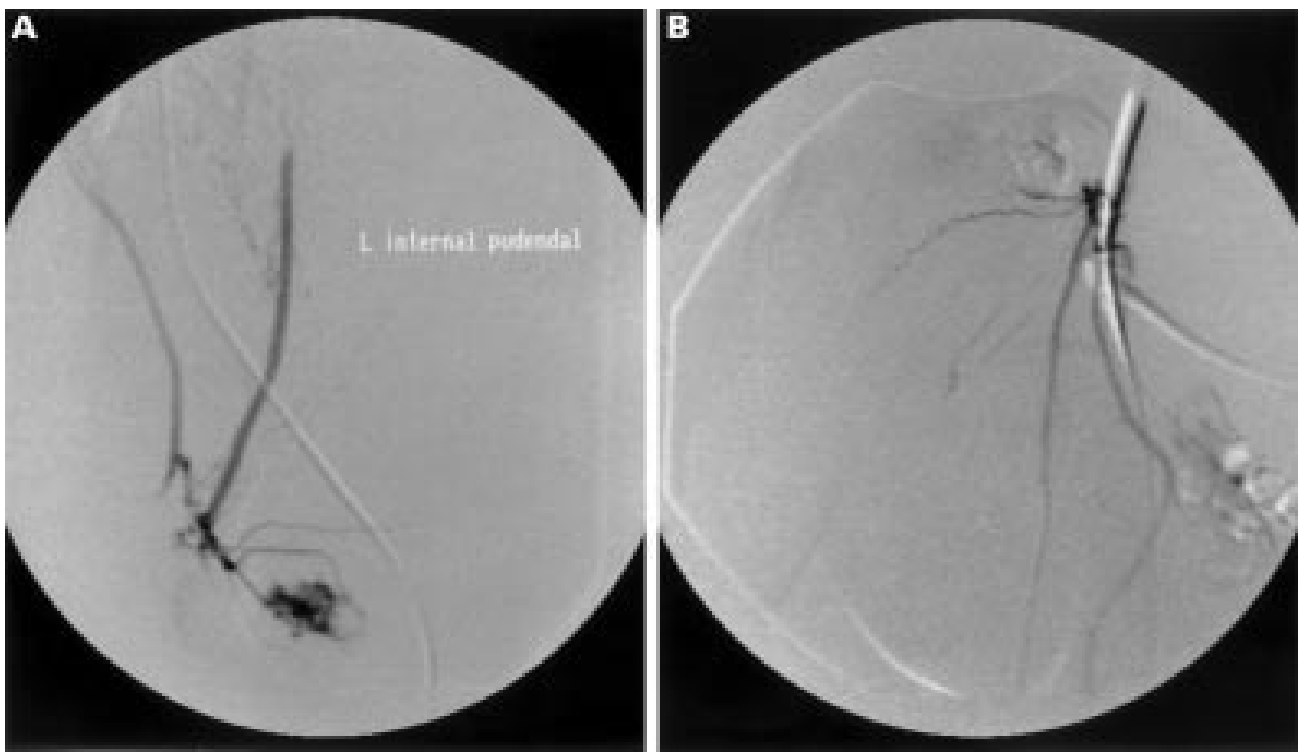

Figure 1 Internal pudendal arteriogram showing a blush of contrast resulting from laceration of the cavernosal artery (A) and after gel foam embolisation (B).

thesia indicated a laceration of the left cavernosal artery (fig 1A) which was selectively embolised with gel foam sponge (fig 1B), resulting in a gradual detumescence of the penis in the following 36 hours. Normal erectile function gradually returned over the next three months.

\section{Discussion}

Priapism is a prolonged penile erection that is unrelated to sexual stimulation. Two forms of priapism are recognised: veno-occlusive or low flow priapism and arterial or high flow priapism. Low flow priapism is the more common and occurs when the corpora cavernosa are engorged as the result of venous outflow obstruction, typically following injection with intracavernosal vasoactive agents in men with erectile dysfunction. The treatment of these patients is well recognised: corporeal aspiration, sympathomimetic drugs, or surgical shunting procedures are usually successful. ${ }^{1}$

In contrast, high flow priapism is rare and has only been reported in a small number of patients. ${ }^{23}$ The condition is caused by trauma to a branch of the cavernosal artery, resulting in a greater arterial inflow to the corpora cavernosa than the venous channels can drain. This rare form of priapism is typically painless because there is no tissue ischaemia. Although cavernosal blood gas analysis may be necessary to distinguish between the two forms of priapism, ${ }^{4}$ the history and physical signs in our patient were characteristic of an arterial aetiology and this was confirmed by Doppler sonography.

Department of Urology, University Hospital of Wales, Cardiff

A Golash R Gray

B J Jenkins

Department of Radiology M S T Ruttley

Correspondence to: Mr B J Jenkins, Ward A5, University Hospital of Wales, Heath Park, Cardiff, Wales 
Although some cases of arterial priapism may resolve spontaneously, ${ }^{5}$ either surgical ligation of the ruptured artery or percutaneous embolisation $^{36}$ has been used to treat most patients with this uncommon disorder. In our patient, diagnostic angiography followed by therapeutic arterial embolisation was successful and, we would suggest, is the initial treatment of choice for post-traumatic arterial priapism.

Contributors: A G, R G, M R, and B J were all involved in the Contributors: A G, R G, M R, and B J were all involved in the
clinical care of this patient and contributed to the writing of the clinical care of this patient and contributed

Take home message

Traumatic priapism is usually due to laceration of a branch of the cavernosal artery. Diagnostic angiography and therapeutic arterial embolisation is the management of choice.

Lue TF, Hellstrom WJG, McAnich JW, et al. Priapism: a 1986;136:104-8

Ricciardi R, Bhatt GM, Cynamon J, et al. Delayed high flow prapism: pathophysiology and management. F Urol 1993;

(15iapis: a spectrum of disease. F Urol 1993;150:968-71.

Kang BC, Lee DY, Byun JY, et al. Post-traumatic arterial arterial embolization. Clin Radiol 1998;53:830-4.

Gudinchet D, Fournier D, Jichlinski P, et al. Traumatic priapism in a child: evaluation with color flow Doppler sonography. F Urol 1992;148:380.

Bastuba MD, Saenz de Tejada I, Dinlenc CZ, et al. Arterial priapism: diagnosis, treatment and long-term follow up. $\mathcal{F}$ Urol 1994:151:1231-7.

\section{British Association of Sport and Exercise Medicine in association with the National Sports Medicine Institute}

\section{Education programme 2000}

General Sports Medicine Course

24-29 September

Lilleshall Hall National Sports Centre, Shropshire (residential)

PGEA and CME will be given

Practical Sport and Medicine Meeting

5-12 October

Club La Santa, Lanzarote (residential)

Advanced Sports Medicine Course

Lilleshall Hall National Sports Centre, Shropshire (residential)

BASEM National Congress: (West Midlands)

3-5 November

Stakis Luxury Puckrup Hall Hotel, Tewkesbury

Intermediate Sports Injury Course-Part 2

19-24 November

Lilleshall Hall National Sports Centre, Shropshire (residential)

8-13 October

PGEA and CME will be given

\section{Current Concepts Meeting on Pre-event Screening}

8-9 December

Cost and location to be confirmed

For further details of these courses please contact Mr Barry Hill, The National Sports Medicine Institute, c/o Medical College of St Bartholomew's Hospital, Charterhouse Square, London EC1M 6BQ.

Tel 02072510583 (ext 237). Fax 0207251 0774. Email: barry.hill@nsmi.org.uk Web site: www.nsmi.org.uk 